\title{
Mitomycin in Choanal Atresia Repair
}

\author{
Ahmed Abdelfattah ${ }^{1^{*}}$ and Ahmed Ibrahim Zaghloul ${ }^{2}$ \\ Department of Otorhinolaryngology, Faculty of Medicine Cairo ${ }^{1}$ and Damietta ${ }^{2}$, Al-Azhar University \\ *Corresponding author: Ahmed Abdelfattah, E-Mail: ahmedfatah10@ hotmail.com
}

\begin{abstract}
Background: choanal atresia is one of congenital anomalies that needs surgical repair. Nasal re-stenosis and obstruction are side effects of endoscopic repair. Mitomycin was proposed to decrease postoperative stenosis and/or obstruction.

Aim of the Work: it was to address the efficacy of adjuvant mitomycin therapy application in providing the postoperative patency in choanal atresia.

Patients and Methods: this study is a record analysis of surgical outcomes of transnasal endoscopic surgical choanal atresia repair in Al-Azhar University Hospitals (Cairo and Damietta). The study included records of 30 children with either uni- or bi-lateral choanal atresia. Eighteen (18) children of themwereoperated upon with adjuvant mitomycin therapy. Meanwhile, records of 12 children were operated uponwithout adjuvant mitomycin andconsidered as a comparison group. Postoperative stenting was carried out in all participants. The collected information included demographic information, associated co-morbidities, operative details, and endoscopic findings. The outcome measures were: granulation tissue formation, need for postoperative dilation and need for revision surgical intervention.

Results: re-stenosis was reported in 11 (28.9\%) patients. The need for revision surgery was reported in $10.3 \%$. The postoperative dilatation was required in $10(25.6 \%)$ patients, and there was no significant difference between mitomycin and comparison groups.

Conclusion and Recommendation: the use of adjunctive mitomycin therapy with endoscopic repair of choanal atresia seems to be effective and safe approach. Multicenter follow up trials should be done to fully evaluate the value (benefits) of adjuvant mitomycin therapy in choanal atresia repair.
\end{abstract}

Keywords: Choanal atresia, endoscopic surgical repair, mitomycin, stent

\section{INTRODUCTION}

Choanal atresia (CA) is a congenital anomaly with female predominance. It presented unilaterally in about $70 \%$ of cases. As neonates are obligatory nasal breathers, early repair of bilateral CA is mandatory ${ }^{(\mathbf{1})}$. The goal of ideal surgical repair isrestoring the normal nasal passagesafely with no damage to adjacent tissues and leads to short hospitalization. Transnasal endoscopic repair is the most widely accepted intervention ${ }^{(2,3)}$. However, a trans-palatal approach remains necessary in some patients (e.g., neonates with severe craniofacial anomalies or very small nasal fossae $)^{(4)}$.

Postoperativestenosis is one of common complications of CA repair surgery, secondary to granulation tissue formation. This stenosis may need dilation by rigid dilators or even balloons and in some occasions (severe stenosis); a revision surgery may be performed. Adjunct therapies were proposed to avoid such problems. Stenting of the chonae ${ }^{(5)}$ and intraoperative topical mitomycinhave been used to decrease postoperative stenosis. However, mitomycin efficacy remains controversial ${ }^{(\mathbf{4 , 6}-\mathbf{8})}$.

\section{AIM OF THE WORK}

It is to address the efficacy of adjuvant mitomycin application in treatment of choanal atresia.

\section{PATIENTS AND METHODS}

Thisresearch is a record analysis study of surgical outcomes of transnasal endoscopic surgical interventional repair of choanal atresia that conducted in Al-Azhar University Hospitals (Cairo and Damietta). The study was approved by the Ethics Board of Al-Azhar University and an informed written consent was taken from each participant in the study.

The data of this study wereretrieved from records of 30 children with either uni- or bi-lateral choanal atresia, either bony or membranous atresias, without any other associated anomalies. These patients were treated with transnasal endoscopic surgical repair of choanal atresia by the authors during the period from January 2014 to November 2018. Eighteen (18) children were surgically managed with adjuvant mitomycin therapy and considered as the studiedmitomycin group. Meanwhile, 12 children were surgically treated without adjuvant mitomycin and considered as a comparison group.

The collected files' data included demographic information, associated co-morbidities, operative details and endoscopic findings.

All cases underwent the surgical intervention under general anesthesia. Nasal decongestion was achieved by oxymetazoline bilateral nasal drops. Nasal endoscopy was done by a telescope $\left(0^{\circ}, 2.7\right.$ 
$\mathrm{mm}$, Karl Storz) through transnasal approach under direct endoscopic vision. A mouth gag may be inserted when needed to facilitate inspection fromthe nasopharyngeal side. The procedure was completed as described by Carter $\boldsymbol{e t}$ al. ${ }^{(9)}$. Briefly, a puncture hole was formed through the membranous atresia. The choanae were then serially dilated by urethral sounds, up to 24 French in size.

Cases with thick bony atresia, which may not be possible to puncture through with suction, so a powered cutting sinus drill bit or a microdebrider was used to open the atretic plate.

A pediatric sinus back biter was used to get rid of the posterior aspect of the bony nasal septum. The rough edges were smoothed with a microdebrider. After dilation, mitomycin Cat a concentration of $0.4 \mathrm{mg} / \mathrm{mL}$ was applied for a total of 3 minutes with a cotton pledget, and then irrigated with saline.Postoperative stenting was performed in all patients then sutured in place and left for 6 weeks. All patients received antibiotics, stents underwent the routine care (normal saline irrigations and suctioning), and patients received regular skin care and observation for ischemic injury of the nares. Finally, topical nasal steroids were started after stent removal.The outcome measures weregranulationtissue formation, need for postoperativedilation and need for revision surgery.

\section{Statistical analysis:}

Statistical Package for Social Science (SPSS) version 20 on IBM compatible computer (SPSS Inc., Chicago, IL, USA) was used for data analysis.Qualitativedata were presented as frequency and percentages, while quantitative data were presented as mean \pm standard deviations $(\mathrm{M} \pm \mathrm{SD})$. Procedures were compared between both groups;
Fisher exact test was used for qualitative data and tstudent test was used for quantitative data. $\mathrm{P}$ value $<0.05$ was the level of significance.

\section{RESULTS}

In the present work, there were $9(30.0 \%)$ males and $21(70.0 \%)$ females. Further,there was no statistically significant difference between mitomycin and comparison groups regarding to sex (males represented $33.3 \%$ and $25 \%$ of mitomycin and comparison groups respectively). The majority of atresia were unilateral (21 cases; $70.0 \%)$ and there was no statistically significant difference between mitomycin and comparison groups regarding laterality. The age ranged from 18 to 48 months in unilateral cases and from 3 to 5 days in bilateral cases. There was no statistically significant difference between mitomycin and comparison groups. The atresia type was bony in $17.9 \%$ and mixed in $82.1 \%$ with no statistically significant difference between mitomycin and comparison groups (table 1).

The outcome revealed that re-stenosis was reported in $11(28.9 \%)$ patients $(20.8 \%$ in mitomycin group and $40.0 \%$ in comparison group; however, the difference did not reach statistical significance level). The need for revision surgery was reported in $10.3 \%$ (4.2\% in mitomycin group compared to $20.0 \%$ in comparison group).

In addition, the postoperative dilatation was required in $10(25.6 \%)$ patients $(16.7 \%$ in mitomycin group and $40.0 \%$ in comparison group). Again, the difference did not reach a statistical significance level (table 2).

Table (1): Characteristics of studied populations

\begin{tabular}{|c|c|c|c|c|c|c|}
\hline & Variable & $\begin{array}{c}\text { Mitomycin } \\
(\mathrm{n}=18 ; 24 \\
\text { procedure })\end{array}$ & $\begin{array}{c}\text { Comparison } \\
(\mathrm{n}=12 ; 15 \\
\text { procedure }) \\
\end{array}$ & $\begin{array}{c}\text { Total } \\
(\mathrm{n}=30 ; 39 \\
\text { procedure })\end{array}$ & $\begin{array}{c}\text { FE } \\
\text { t-test }\end{array}$ & $P$ value \\
\hline \multirow{2}{*}{ Sex } & Male [n (\%)] & $6(33.3 \%)$ & $3(25.0 \%)$ & $9(30.0 \%)$ & \multirow{2}{*}{$\mathbf{F E}$} & \multirow{2}{*}{0.7} \\
\hline & Female [n (\%)] & $12(66.7 \%)$ & $9(75.0 \%)$ & $21(70.0 \%)$ & & \\
\hline \multirow{2}{*}{ Laterality } & Unilateral [n(\%)] & $12(66.7 \%)$ & $9(75.0 \%)$ & $21(70.0 \%)$ & \multirow{2}{*}{ FE } & \multirow{2}{*}{0.7} \\
\hline & Bilateral [n (\%)] & $6(33.3 \%)$ & $3(25.0 \%)$ & $9(30.0 \%)$ & & \\
\hline \multirow[t]{2}{*}{ Age } & 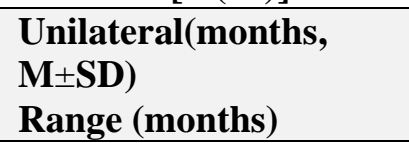 & $\begin{array}{c}26.25 \pm 9.93 \\
18-48\end{array}$ & $\begin{array}{c}28.11 \pm 6.29 \\
19-38\end{array}$ & $\begin{array}{c}27.04 \pm 8.42 \\
18-48\end{array}$ & -0.71 & 0.24 \\
\hline & $\begin{array}{l}\text { Bilateral (days, } \mathrm{M} \pm \mathrm{SD} \text { ) } \\
\text { Range (days) }\end{array}$ & $\begin{array}{c}3.83 \pm 0.75 \\
3-5 \\
\end{array}$ & $\begin{array}{l}4.0 \pm 1.0 \\
3-5\end{array}$ & $\begin{array}{c}3.88 \pm 0.78 \\
3-5 \\
\end{array}$ & -0.56 & 0.28 \\
\hline \multirow{2}{*}{$\begin{array}{l}\text { Type of } \\
\text { atresia }\end{array}$} & Bony [n (\%)] & $3(12.5 \%)$ & $4(26.7 \%)$ & $7(17.9 \%)$ & \multirow{2}{*}{ FE } & \multirow{2}{*}{0.39} \\
\hline & Mixed [n (\%)] & $21(87.5 \%)$ & $11(73.3 \%)$ & $32(82.1 \%)$ & & \\
\hline
\end{tabular}

FE: Fisher exact test

Table (2): Outcome among studied populations 


\begin{tabular}{|c|c|c|c|c|c|c|}
\hline \multicolumn{2}{|c|}{ Variable } & $\begin{array}{r}\text { Mitomycin } \\
(n=18 ; 24\end{array}$ & $\begin{array}{c}\text { Comparison } \\
(\mathrm{n}=12 ; 15\end{array}$ & $\begin{array}{c}\text { Total } \\
(n=30 ; 39\end{array}$ & $\begin{array}{l}\text { Fisher } \\
\text { Exact }\end{array}$ & $\begin{array}{c}\mathbf{P} \\
\text { value }\end{array}$ \\
\hline \multirow{2}{*}{ Outcome } & Re-stenosis [n (\%)] & $5(20.8 \%)$ & $6(40.0 \%)$ & $11(28.2 \%)$ & \multirow{2}{*}{ FE } & \multirow{2}{*}{0.27} \\
\hline & Open [n (\%)] & $19(79.2 \%)$ & $9(60.0 \%)$ & $28(71.8 \%)$ & & \\
\hline \multicolumn{2}{|c|}{ Need for revision surgery [n (\%)] } & $1(4.2 \%)$ & $.0 \%)$ & $3 \%)$ & FE & 0.27 \\
\hline \multicolumn{2}{|c|}{ Postoperative dilatation [n (\%)] } & $4(16.7 \%)$ & $6(40.0 \%)$ & $10(25.6 \%)$ & FE & 0.14 \\
\hline
\end{tabular}

\section{DISCUSSION}

The effectiveness and safety of endoscopic repair of choanal atresia has been well established ${ }^{(4-}$ 6,10). However, postoperative formations of scar, adhesion or granulation tissue are reported and could be an etiology of nasal obstruction and revision surgery. The use of adjuvant stenting and mitomycin has been tried in attempt to reduce such problems ${ }^{(9)}$.

The present work was conducted to review the outcome of mitomycin as an adjuvant in repair of choanal atresia. Results of the present work revealed that, choanal atresia had a female sex predilection, usually unilateral with mixed type predominance. In addition, intraoperative mitomycin application as an adjuvant therapy in choanal atresia repair is superior than non-application of mitomycin. However, the difference did not becomestatistically significant. This could be explained by small number of cases included in the present work, which could not be avoided due to rarity of the disease.

Results of the present trial are comparable to those reported by Karligkiotis et al. ${ }^{(11)}$ who reported that, fifty-five $(65.5 \%)$ cases presented with unilateral CA and $29(34.5 \%)$ caseswith bilateral CA. In addition, Brown et al. ${ }^{(\mathbf{1 2})}$ reported that, choanal atresia is more frequent in females, with unilateral presentation being more common $(60 \%)$. The atretic plate may be bony $(\sim 30 \%)$ or mixed; bonymembranous $(\sim 70 \%)$.

The idea about the use of mitomycin in such patients is that, it acts as an inhibitor of the scar. It targets tissue in a selective manner because it needs modification by intracellular enzymes to its active intermediates ${ }^{(13)}$. Mitomycin application seems to inhibit the growth and migration of fibroblasts and permits for healing with reduction of scar formation (7).

Results of the present work agree with Bozkurt et al. ${ }^{(6)}$ who concluded that, mitomycin appears to hasten the surgicaloutcome of choanal atresia and decreases re-stenosis rate without any complications. In addition, Pardo Romero et al..$^{(14)}$ reported that mitomycin not only improves the patency butalso reduces the need for dilatations and revision surgery. On the other hand, Kubba et al. ${ }^{(15)}$ reported that, mitomycin had no additional benefit other than nasal steroids and stents in their 46-patient series. The possible explanation for such apparent contradiction could be attributed to the fact that, they compared mitomycin with other antifibrotic drugs (corticosteroids). However, results of present work agree with Carter et $\boldsymbol{a l l}_{\mathbf{.}}{ }^{(\mathbf{9 )}}$ who reported that, eleven total sides were treated with mitomycin; $18 \%$ of sides treated with mitomycin required postoperative dilatation vs. $40 \%$ of those sides not treated with mitomycin.However, there was no significant statistical difference. Revision surgery was not needed in any sides treated with mitomycin, while $3 / 15(20 \%)$ of the sides not treated required revision surgery $(\mathrm{p}=0.24)$.

\section{CONCLUSION AND RECOMMENDATION}

The use of adjunctive mitomycin therapy with endoscopic repair of choanal atresia seems to be effective and safe as it reduces granulation tissue formation, with lower rate of re-stenosis and fewer revision surgeries. However, further multicenter follow up randomized trials on big number of patients should be done to fully investigate the benefits of adjuvant mitomycin therapy in choanal atresia repair.

\section{REFERENCES}

1. Moreddu E, Rossi ME, Nicollas R et al. (2019): Prognostic Factors and Management of Patients with Choanal Atresia. J Pediatr., 204:234-239.e1.

2. Uzomefuna V, Glynn F, Al-Omari B et al. (2012): Transnasal endoscopic repair of choanal atresia in a tertiary care centre: a review of outcomes. Int J Pediatr Otorhinolaryngol., 76:613-7.

3. Gulsen S, Baysal E, Celenk F et al. (2017): Treatment of congenital choanal atresia via transnasal endoscopic method. J Craniofac Surg., 28:338-42.

4. Newman JR, Harmon P, Shirley WP et al. (2013): Operative management of choanal atresia: a 15-year experience. JAMA Otolaryngol Head Neck Surg., 139: 71-75.

5. Bedwell JR and Choi SS (2012): Are stents necessary after choanal atresia repair? Laryngoscope, 122: 2365-2366.

6. Bozkurt MK, Keles B, Azimov A et al. (2010): The use of adjunctive topical mitomycin in 
endoscopic congenital choanal atresia repair. Int $\mathbf{J}$ Pediatr Otorhinolaryngol., 74: 733-736.

7. Teissier N, Kaguelidou F, Couloigner V et al. (2008): Predictive factors for success after transnasal endoscopic treatment of choanal atresia. Arch Otolaryngol Head Neck Surg., 134: 57-61.

8. Prasad M, Ward RF, April MM et al. (2002): Topical mitomycin as an adjunct to choanal atresia repair. Arch Otolaryngol Head Neck Surg., 128 (4): 398-400.

9. Carter JM, Lawlor C, Guarisco JL (2014): The efficacy of mitomycin and stenting in choanal atresia repair: A 20-year experience. Int $\mathrm{J}$ Pediatr Otorhinolaryngol., 78: 307-311.

10. Wootten CT, Elluru RE (2010): Congenital malformations of the nose.In: PW Flint (Ed.), $5^{\text {th }}$ ed., Cummings Otolaryngology Head Neck Surgery, Vol. 3, Mosby Elsevier, Philadelphia, PA, pp. 2686-2696. 11. Karligkiotis A, Farneti P, Gallo S et al. (2017): An Italian multicentre experience in endoscopic endonasal treatment of congenital choanal atresia: Proposal for a novel classification system of surgical outcomes. J Cranio-Maxillo-Facial Surg., 45: 101825.

12. Brown OE, Pownell P, Manning SC (1996): Choanal atresia: a new anatomic classification and clinical management applications. Laryngoscope, 106: 97-101.

13. McLeod IK, Brooks DB, Mair EA (2003): Revision choanal atresia repair. Int $\mathbf{J}$ Pediatr Otorhinolaryngol., 67: 517-22.

14. Pardo Romero G, Mogollon Cano-Cortes T, Pando Pinto JM et al. (2007): Endoscopic treatment for choanal atresia. Acta Otorrinolaringol Esp., 58: 34-36.

15. Kubba H, Bennett A, Bailey CM (2004): An update on choanal atresia surgery at Great Ormond street hospital for children: preliminary results with mitomycin $\mathrm{C}$ and the KTP laser. Int $\mathrm{J}$ Pediatr Otorhinolaryngol., 68: 939-945. 